Rabaska

Revue d'ethnologie de l'Amérique française

\title{
L'Apport des prêtres et religieux au patrimoine des minorités. Parcours comparés Bretagne/Canada français
}

\section{Jean Simard}

Volume 10, 2012

URI : https://id.erudit.org/iderudit/1013553ar

DOI : https://doi.org/10.7202/1013553ar

Aller au sommaire du numéro

Éditeur(s)

Société québécoise d'ethnologie

ISSN

1703-7433 (imprimé)

1916-7350 (numérique)

Découvrir la revue

Citer ce compte rendu

Simard, J. (2012). Compte rendu de [L’Apport des prêtres et religieux au patrimoine des minorités. Parcours comparés Bretagne/Canada français]. Rabaska, 10, 216-221. https://doi.org/10.7202/1013553ar d'utilisation que vous pouvez consulter en ligne. 
Colloques et rassemblements

\section{L'Apport des prêtres et religieux au patrimoine des minorités. Parcours comparés Bretagne/Canada français}

JEAN SIMARD

Société québécoise d'ethnologie

Des ethnologues de 1'Université Sainte-Anne à Pointe-de-l'Église (Nouvelle-Écosse), de l'Université de Bretagne occidentale à Brest (France), de 1'Université de Moncton (Nouveau-Brunswick) et de la Société québécoise d'ethnologie (Québec) ont organisé à Pointe-de-1'Église du 19 au 21 octobre, et à Brest les 17 et 18 novembre 2011, des journées internationales d'étude ayant pour thème « L'Apport des prêtres et religieux au patrimoine des minorités. Parcours comparés Bretagne/Canada français ». Le comité scientifique de ces réunions était composé de Jean-Pierre Pichette, Chaire de recherche en oralité des francophonies minoritaires (COFRAM) de 1'Université SainteAnne, Ronald Labelle, Chaire McCain en ethnologie acadienne (CREMEA) de l'Université de Moncton, Jean Simard, Société québécoise d'ethnologie (SQE), Jean-François Simon et Fañch Postic, Centre de recherche bretonne et celtique (CRBC) de l'Université de Bretagne occidentale. Près d'une trentaine d'experts des deux communautés minoritaires ont présenté des communications et ont échangé leurs points de vue.

Deux grandes conclusions se sont dégagées de ces rencontres. Tout d'abord que l'intérêt des prêtres et des religieux pour la collecte ethnographique accuse un net décalage chronologique entre la Bretagne et le Canada français alors même que l'histoire religieuse des deux communautés montre des parallélismes saisissants. Ensuite que les premières collectes ethnographiques n'étaient pas tout à fait neutres. Elles étaient des outils d'apostolat religieux puis de défense et de promotion de l'identité. À ce chapitre, la Bretagne et le Canada français n'accusent guère de différences. Mais à mesure que nous avançons vers le présent, l'esprit scientifique a gagné du terrain de telle sorte que ces religieux ont délaissé peu à peu le militantisme des premiers temps. 


\section{Décalage chronologique des collectes ethnographiques}

Fañch Postic et Jean-Pierre Pichette ont bien annoncé ce cadre dans leur présentation d'ouverture. Les premières collectes bretonnes par des religieux voient le jour à la fin du XVIII ${ }^{\mathrm{e}}$ siècle tandis qu'elles se multiplient après 1839, à la suite de la publication du Barzaz-Breiz de Théodore Hersart de La Villemarqué pour s'achever à la fin du XIX et au début du XXe siècle avec les travaux de Jean-Marie Perrot et de François Duine en particulier. Les collectes de l'abbé François Falc'hun diffèrent un peu des précédentes puisqu'elles sont faites dans le cadre institutionnel de la mission de folklore musical de 1939 en Basse-Bretagne entreprise par le Musée national des arts et traditions populaires de Paris.

L'histoire de la collecte ethnologique au Canada français, affirme JeanPierre Pichette, ne saurait faire fi de la contribution des prêtres et des religieux, comme Henri-Raymond Casgrain qui dès 1860 publiait dans Le Courrier $d u$ Canada des contes et légendes retenues de son enfance, et après lui Camille Roy et les écrivains du terroir qui, sans être des collecteurs, transmettaient des savoirs issus de leur culture d'origine. Mêmes remarques de la part d'Aurélien Boivin qui souligne l'apport significatif des Lionel Groulx (Les Rapaillages, 1916), Noël Gosselin (Les Choses qui s'en vont, 1918) et frère Marie-Victorin (Récits laurentiens, 1919) dans l'édification d'une littérature qui défendait les valeurs traditionnelles. Il faut attendre les premières années du $\mathrm{XX}^{\mathrm{e}}$ siècle pour voir apparaître un premier véritable mouvement de collecte autour des lexicographes de la Société du parler français au Canada, dont neuf des vingt-quatre membres fondateurs étaient précisément des clercs. D'autres suivront dans les domaines de la généalogie et de l'histoire locale, comme $\mathrm{M}^{\mathrm{gr}}$ Victor Tremblay, le père de 1'histoire du Saguenay-Lac-Saint-Jean qui fonda la Société historique du Saguenay ; de la muséographie pratiquée par l'abbé Paul-André Leclerc qui mit sur pied en 1974 le Musée François-Pilote de La Pocatière, dont Philippe Dubé nous a dit qu'il prenait la relève d'une pareille institution dont les origines remontaient à 1881 au sein du collège classique de Sainte-Anne-de-La Pocatière. Pouvons-nous conclure de ce qui précède que le Canada français est au $\mathrm{Xx}^{\mathrm{e}}$ siècle ce que fut la Bretagne au $\mathrm{XIX}^{\mathrm{e}}$ siècle?

\section{Synchronie de la situation socioreligieuse des deux communautés}

L'écart chronologique dans l'intérêt des prêtres et religieux pour la collecte ethnographique ne trouve pas son pendant dans les attitudes socioreligieuses, fort comparables cette fois-ci, dans les deux communautés minoritaires. Si, comme on l'a généralement affirmé, la Révolution française, et dans sa suite une publication légitimiste comme le Feiz-ha-Breiz et les législations sur 
l'enseignement de la langue puis la séparation des Églises et de l'État au début $\mathrm{du} \mathrm{Xx}^{\mathrm{e}}$ siècle se sont soldées en Bretagne par un renforcement de la religion traditionnelle et une autorité accrue du clergé qui se serait présenté comme le défenseur de la religion et de l'identité affichées dans le slogan « Catholiques et Bretons toujours ", ces mêmes événements ont eu au Canada français le même effet de repoussoir. Après 1789, l'Église du Québec faisait prier ses fidèles pour le retour de la monarchie dans la mère patrie, comme plus tard elle accueillera à bras ouverts les communautés religieuses réfractaires, celles en particulier qui venaient de Bretagne. Plus encore, c'est de l'époque des législations du « père Combes » que les historiens du Québec, presque tous religieux jusqu'en 1950, ont développé le mythe des origines bretonnes de la population canadienne au XVII ${ }^{\mathrm{e}}$ siècle.

Cette synchronie des deux histoires socioreligieuses perdure jusqu'au milieu du Xx ${ }^{e}$ siècle et après. Selon Georges Minois (Histoire religieuse de la Bretagne, 1991), de 1900 à 1940, la Bretagne fournit aux missions étrangères 1752 religieuses, 1056 prêtres et 387 frères enseignants, dont un bon nombre est destiné au Québec et à l'Acadie. Du côté des fidèles, la pratique régulière atteint $53 \%$ dans les années 1950, un record pour la France de cette époque, tandis que $67 \%$ vont à l'église pour les grands événements : baptêmes, mariages et enterrements. Du côté du Québec, selon les calculs de Jean Hamelin (Histoire du catholicisme québécois. Le XXe siècle. De 1940 à nos jours, 1984), les effectifs du clergé connaissent la même croissance : en 1932 ils sont 4086 prêtres, séculiers et réguliers, à desservir en moyenne 603 fidèles ; en 1962, 7908 prêtres pour 586 fidèles. Même courbe chez les religieux : en 1931, 25332 religieux, hommes et femmes, pour 97 personnes chacun; en 1961, 45253 pour 102. Le catholicisme dans le Québec du premier $\mathrm{Xx}^{\mathrm{e}}$ siècle, on le voit, tient la même place que dans le pays breton. À cet égard, nous aurions sans doute intérêt à comparer les bilans de cette période de l'histoire religieuse présentés par Yann Celton à partir des Conférences ecclésiastiques du diocèse de Quimper et Léon (1953) avec ceux de la Commission d'étude sur les laïcs et l'Église du Québec (1968), présidée par le sociologue Fernand Dumont, qui visita tous les diocèses et reçut 800 mémoires. Puis arrivent les années 1960, dont nous a parlé Yvon Tranvouez, où la chute radicale des indices sera la même dans les deux populations, où des sociologues comme le chanoine Fernand Boulard et le même Fernand Dumont, puis des ethnologues comme les dominicains Serge Bonnet et Benoît Lacroix chercheront alors pour la France, et dans une moindre mesure pour le Québec, des solutions pour l'avenir dans le renouvellement de la pastorale d'action catholique ou dans la revalorisation de la religion populaire.

Pourquoi les prêtres et les religieux de Bretagne et du Canada français, vu qu'ils bénéficiaient d'un statut comparable dans leur communauté respective, 
ne se sont pas intéressés aux mêmes choses aux mêmes moments ? Raisons de conjonctures certainement. L'Église du Québec a dû se reconstruire au $\mathrm{XIX}^{\mathrm{e}}$ siècle après une longue période de latence qui a suivi le changement d'allégeance coloniale en 1760 et l'échec du projet libéral et démocratique du mouvement patriote des années 1837-1839. Nostalgique de la France monarchique d'Ancien Régime, elle a vu au tournant du $\mathrm{Xx}^{\mathrm{e}}$ siècle l'occasion de renouer avec la vieille mère patrie en accueillant ses héros catholiques et conservateurs venus lui prêter main forte dans la défense et l'illustration de la langue française. C'est de cette époque que date le concept de « la langue gardienne de la foi » qui réveillera au Québec, en Acadie et même en Nouvelle-Angleterre, selon Normand Beaupré, autour de militants tels que l'abbé Adrien Verret, le père Henri d'Arles et sœur Mary-Carmel Therriault, l'intérêt des clercs pour la chose nationale et les collectes ethnographiques. D'après Barry-Jean Ancelet, pour des raisons difficiles à expliquer, la Louisiane française n'aurait pas fait écho à ce mouvement venu du nord, pas plus d'ailleurs qu'elle n'aurait bénéficié de l'aide de ses prêtres et religieux pour la protection de la langue et de la culture des origines. Même son de cloche dans l'Ouest canadien : « Nous étions trop occupés à survivre pour s'occuper de notre culture ", confiait à Dominique Sarny son informatrice Irène Thomas.

\section{L'esprit scientifique supplante peu à peu le militantisme des premiers temps}

Nous devons les premières collectes ethnographiques en Amérique du Nord aux missionnaires venus de France. Elles ont pour cible les Amérindiens du Canada que documentent principalement les jésuites et plus tard les oblats provenant surtout de Bretagne. À proprement parler, ce que nous qualifions ici de collecte sont plutôt des témoignages qui atterrissent dans des récits de voyage ; les plus célèbres de tous étant les Relations des jésuites rédigées de 1632 à 1672. De 1900 à 1940, note Samuel Gicquel, 661 prêtres et religieux oblats quittèrent leur Bretagne natale pour évangéliser les Amérindiens du Canada et en ramenèrent des documents qui ont pour point commun d'avoir été rédigés dans une optique apologétique. Le cas d'Émile Petitot, oblat venu de Marseille, est différent puisqu'il a véritablement fait, tout à la fois et distinctement, œuvre de missionnaire et d'ethnologue en publiant des récits de voyage illustrés de ses propres dessins décrivant la culture matérielle des populations visitées. En cela il prenait la relève des premiers jésuites, Claude Chauchetière et Louis Nicolas, qui avaient laissé des témoignages visuels de la vie quotidienne des Hurons et des Iroquois du XVII ${ }^{e}$ siècle. Vinrent ensuite, pour l'ethnologie de Soi, les collectes de chansons populaires, pratiquées au Canada français par des professeurs de collège et des membres du clergé tels que les Burque et Gadbois, en Bretagne par les Buléon, Guillevic et Le Goff, 
à Paris par François Cadic auprès des exilés bretons, et de façon plus générale les travaux à caractère monographique des curés de village dont nous a parlé François Ploux, qui traitent d'histoire locale et de vie religieuse, mais aussi de traditions et de folklore. Tout aussi importantes et significatives qu'elles furent pour les archives ethnographiques de la fin du XIX ${ }^{\mathrm{e}}$ siècle, elles n'en étaient pas moins destinées aussi à l'apostolat. Au début du Xxe, les travaux d'un Jean-Marie Perrot visaient plutôt des objectifs de revitalisation de la nation bretonne en réponse aux attaques du pouvoir laïc et centralisateur de Paris, ce qui n'enlève rien à leur mérite. De même en est-il du Canada français. En 1902, l'année même où Émile Combes, ministre de l'Intérieur et des cultes de la III $^{\mathrm{e}}$ République, ordonne aux prêtres de Basse-Bretagne d'utiliser le français plutôt que le breton au catéchisme et au prône du dimanche, Adjutor Rivard et l'abbé Stanislas Lortie fondent à Québec la Société du parler français au Canada dont l'une des missions est de s'occuper de « l'examen des dangers qui menacent le parler français au Canada : influence du milieu, contact habituel et nécessaire avec des idiomes étrangers, déformation graduelle du langage populaire laissé à lui-même, tendances décadentes de la langue dans la littérature, le commerce et l'industrie modernes, et goût trop prononcé pour quelques formes vieillies ". Ici encore, l'attitude défensive n'infirme en rien la valeur scientifique de l'œuvre à laquelle s'est associé un nombreux clergé, comme le démontre la réputation jamais ternie du Glossaire du parler français au Canada que publiait cette Société en 1930. Les efforts de la Société du parler français au Canada sont bien sûr à mettre en parallèle avec ceux de l'Église bretonne, qui, dès le XVI ${ }^{\mathrm{e}}$ siècle, a voulu créer une langue de culture avec ce «misérable patois tout farci [qu'il était devenu au XVIII ${ }^{\mathrm{e}}$ siècle] de mots français ».

L'ethnologie de Soi traverse aussi les films documentaires des prêtres québécois Albert Tessier et Maurice Proulx qui, en dépit de leur intérêt ethnographique incontestable, n'en visaient pas moins des objectifs de propagande religieuse et nationale. Même constatation pour l'œuvre du père Louis Pinck en Lorraine dont on nous a dit que la politique linguistique et les préoccupations religieuses ont été au centre de ses préoccupations de collecteur, comme aussi pour l'usage des mélodies populaires dans les congrégations fondées par Grignion de Montfort et qui ont essaimé de la France vers le Canada.

Les générations qui ont pris la relève au milieu $\mathrm{du} \mathrm{Xx}^{\mathrm{e}}$ siècle ont généralement opté pour des entreprises libérées de toute intention religieuse ou nationale. De façon générale, admettons avec Martin Meunier que beaucoup de religieux et de clercs du Canada français de ces années d'après-guerre, tels les Ambroise Lafortune et Émile Legault, Marcel-Marie Desmarais et Victor Lelièvre - d'origine bretonne celui-là - ont résolument pris parti en 
faveur de la culture populaire et de l'inculturation du message évangélique. Les travaux d'Anselme Chiasson et de Germain Lemieux et les collectes initiées par Luc Lacourcière et $\mathrm{M}^{\text {gr }}$ Félix-Antoine Savard des Archives de folklore de l'Université Laval ont participé de cet esprit nouveau qui a inspiré bon nombre de religieux ; pensons plus particulièrement ici aux religieuses Marie-Ursule, Catherine Jolicœur et Denise Rodrigue, qui depuis les années 1950 y ont préparé des thèses. Soulignons au passage que Denise Rodrigue a livré devant l'assemblée réunie à l'Université Sainte-Anne de Pointe-del'Église un témoignage des plus convaincants sur sa démarche d'ethnologue dénuée de toute intention que son statut de religieuse aurait pu influencer. Du côté breton, à la fin du XIX ${ }^{\mathrm{e}}$ siècle déjà, mais de façon analogue, le père François Duine rédige à partir de ses collectes nombre d'articles dans les revues savantes de sa province d'origine et dans la parisienne Revue des traditions populaires tandis qu'il mène une véritable carrière de scientifique qui dépasse les frontières mêmes de la France. S'ajoutent, pour le $\mathrm{Xx}^{\mathrm{e}}$ siècle, le chanoine Pérennès et, bien sûr, l'abbé Falc'hum.

Au final, si les premières collectes ethnographiques des prêtres et religieux des deux communautés ont été motivées par des intentions apostoliques ou nationalistes, elles n'en demeurent pas moins des collectes. Il appartient désormais aux scientifiques de faire leur métier, c'est-à-dire de critiquer leurs sources et de dégager ce qui doit être justement considéré pour l'étude comparée du patrimoine des minorités de la Bretagne et du Canada français. 